\title{
Inequalities in pediatric avoidable hospitalizations between Aboriginal and non-Aboriginal children in Australia: a population data linkage study
}

Kathleen Falster ${ }^{1,2,3^{*}}$ (D), Emily Banks ${ }^{1,2}$, Sanja Lujic ${ }^{3,4}$, Michael Falster ${ }^{3,4}$, John Lynch ${ }^{5}$, Karen Zwi ${ }^{6,7}$, Sandra Eades ${ }^{8}$, Alastair H. Leyland ${ }^{9}$ and Louisa Jorm ${ }^{3,4}$

\begin{abstract}
Background: Australian Aboriginal children experience a disproportionate burden of social and health disadvantage. Avoidable hospitalizations present a potentially modifiable health gap that can be targeted and monitored using population data. This study quantifies inequalities in pediatric avoidable hospitalizations between Australian Aboriginal and non-Aboriginal children.

Methods: This statewide population-based cohort study included 1121440 children born in New South Wales, Australia, between 1 July 2000 and 31 December 2012, including 35609 Aboriginal children. Using linked hospital data from 1 July 2000 to 31 December 2013, we identified pediatric avoidable, ambulatory care sensitive and non-avoidable hospitalization rates for Aboriginal and non-Aboriginal children. Absolute and relative inequalities between Aboriginal and non-Aboriginal children were measured as rate differences and rate ratios, respectively. Individual-level covariates included age, sex, low birth weight and/or prematurity, and private health insurance/patient status. Area-level covariates included remoteness of residence and area socioeconomic disadvantage.

Results: There were 365386 potentially avoidable hospitalizations observed over the study period, most commonly for respiratory and infectious conditions; Aboriginal children were admitted more frequently for all conditions. Avoidable hospitalization rates were $90.1 / 1000$ person-years ( $95 \%$ Cl, 88.9-91.4) in Aboriginal children and 44.9/1000 person-years (44.8-45.1) in non-Aboriginal children (age and sex adjusted rate ratio $=1.7(1.7-1.7))$. Rate differences and rate ratios declined with age from 94/1000 person-years and 1.9, respectively, for children aged $<2$ years to 5/1000 person-years and 1.8, respectively, for ages 12-<14 years. Findings were similar for the subset of ambulatory care sensitive hospitalizations, but in contrast, non-avoidable hospitalization rates were almost identical in Aboriginal (10.1/1000 person-years, (9.6-10.5)) and non-Aboriginal children (9.6/1000 person-years (9.6-9.7)).

Conclusions: We observed substantial inequalities in avoidable hospitalizations between Aboriginal and non-Aboriginal children regardless of where they lived, particularly among young children. Policy measures that reduce inequities in the circumstances in which children grow and develop, and improved access to early intervention in primary care, have potential to narrow this gap.
\end{abstract}

Keywords: Indigenous health, Avoidable hospitalisations, Preventable hospitalisations, Child health, Inequalities

\footnotetext{
* Correspondence: kathleen.falster@anu.edu.au

${ }^{1}$ National Centre for Epidemiology and Population Health, Australian National University, Canberra, Australia

${ }^{2}$ The Sax Institute, Sydney, Australia

Full list of author information is available at the end of the article
} International License (http://creativecommons.org/licenses/by/4.0/), which permits unrestricted use, distribution, and reproduction in any medium, provided you give appropriate credit to the original author(s) and the source, provide a link to the Creative Commons license, and indicate if changes were made. The Creative Commons Public Domain Dedication waiver (http://creativecommons.org/publicdomain/zero/1.0/) applies to the data made available in this article, unless otherwise stated. 


\section{Background}

It is well established that Australian Aboriginal children start life with a disproportionate burden of social and health disadvantage [1-3]. The early life disadvantage experienced by Aboriginal children is a precursor to adverse outcomes later in life. Aboriginal Australians experience worse health, development, education and employment outcomes than non-Aboriginal Australians through childand adult-hood [1, 2, 4-7]. There is an identified need for better evidence for targeting and evaluating the impact of policy, programs and services on closing modifiable health gaps during early childhood [8].

Routinely collected population data can provide unique insights into the magnitude and nature of health problems affecting large numbers of people, as well as making visible the experience of smaller sub-populations. Rates of avoidable hospitalization were originally conceived as an indicator of access to quality out-of-hospital care [9]. These indicators use routinely collected hospital data and usually include a set of diagnosis and procedure codes for conditions that are considered amendable to non-hospital interventions. Like many countries, Australian government agencies routinely report on avoidable hospitalizations for a range of acute, chronic and vaccine-preventable conditions [10]. However, when it comes to children, the Australian indicator may have limited relevance because it includes a number of predominantly adult diseases [10].

The United States Agency for Healthcare Research and Quality first published a set of 'Pediatric Quality Indicators' to identify hospitalizations in children that may be avoidable via changes at the health system or provider level in 2006 [11]. More recently, a pediatric avoidable hospitalization indicator was developed in New Zealand that reframed the concept of 'avoidable' to include conditions that might be influenced not only by primary care, but also broader policy measures, such as provision of affordable and quality housing, childcare and income support [12]. This broader definition of avoidable hospitalizations is useful because it avoids potentially unfair and unrealistic expectations about the extent to which reductions in hospitalizations might be achieved through primary care alone [12].

To our knowledge, Australian children have been included in few studies of avoidable hospitalizations to date [13-17], and only two have provided a breakdown by Aboriginal status $[16,17]$. A study of aggregate hospital separation data from five de-identified Australian states and territories in 1993-94 reported higher rates of hospitalization for select child-relevant ambulatory care sensitive conditions in Aboriginal compared with nonAboriginal children [17]. Aboriginal 0-14 year old children were also found to have higher avoidable hospitalization rates than their non-Aboriginal peers in the Northern Territory in 1998-2006, although a pediatric indicator was not used [16]. Moreover, rates were mostly reported for broad age groups, which is problematic because pediatric avoidable hospitalization rates are highest in the first two years of life [18]. Because of the identified need to target and monitor modifiable health gaps between Australian Aboriginal and non-Aboriginal children, we aim to quantify inequalities in pediatric avoidable hospitalizations between Aboriginal and non-Aboriginal children in the most populous state of Australia, New South Wales (NSW), by applying a pediatric avoidable hospitalization indicator to linked hospital data for children born between July 2000 and December 2012.

\section{Methods}

\section{Data sources}

We used hospital data from the NSW Admitted Patients Data Collection, which includes records of all separations from public and private hospitals and day procedure centers in NSW. Each record represents an episode of care that ends when a patient is transferred to another type of care, discharged from hospital, or dies. Patient demographics and multiple diagnoses and procedures are recorded for each separation. Diagnoses are coded according to the Australian modification of the International Statistical Classification of Diseases and Related Problems 10th Revision (ICD-10-AM) [19] and procedures according to the Australian Classification of Health Interventions [19]. We also used death registration data from the NSW Register of Births, Deaths and Marriages to ascertain children who died during the study period. Approval to link and use these data was obtained from the relevant data custodians (NSW Ministry of Health and NSW Register of Births, Deaths and Marriages) prior to seeking ethical approval.

Data were linked by the NSW Centre for Health Record Linkage using probabilistic methods that match identifiers common to the records being linked (e.g. name, sex, date of birth, address) [20]. Only a de-identified unique project person number and information about hospitalizations and/or deaths that occurred between 1 July 2000 and 31 December 2013 were released to the researchers.

\section{Setting}

NSW is Australia's most populous state. The 2006 Australian Census, which is the approximate mid-point for this study period, estimated approximately 6.8 million residents in NSW, including almost 150000 (2.2\%) Aboriginal and/or Torres Strait Islander people [21]. Henceforth, we refer to Aboriginal and/or Torres Strait Islander people as 'Aboriginal' because Torres Strait Islander people accounted for $0.1 \%$ of the NSW population in 2006 [21]. In 2006, $73 \%$ of the NSW population lived in a major city, $27 \%$ lived in regional areas, and less than $1 \%$ lived in remote areas [21]. In contrast, $43 \%$ of the NSW Aboriginal population lived in a major city in 
2006, 52 \% lived in regional areas, and $5 \%$ lived in remote areas [21].

Australia's universal public health insurance scheme (Medicare) covers the cost of necessary health care to individuals admitted as public patients in public hospitals [22]. The Medicare Benefits Schedule sets fees for medical services provided in primary care settings; however, there is variation in the amount and method in which patients are charged for these services. General practitioners (GPs) can directly bill Medicare for services provided (known as 'bulk billing'), in which case the patient incurs no cost. GPs also have the option to charge the patient the Medicare Benefits Schedule fee, and the patient may seek reimbursement from Medicare. The GP is also entitled to charge more than the Medicare Benefits Schedule fee, in which case the patient incurs the cost of the 'gap' between the charged amount and the Medicare Benefits Schedule fee.

\section{Study population}

Children and their records were included in this analysis if they were born in a NSW hospital between 1 July 2000 and 31 December 2012, and their area of residence was within the state of NSW $(n=1$ 124 717). We defined birth admissions as hospital records with a 'live born infant' ICD-10-AM diagnosis code (i.e. Z38) or a date of birth within the hospital admission and separation dates. From this group, 3277 children were excluded because: their sex was coded as indeterminate or missing $(n=34)$; there were discrepancies in their date of birth, admission and/or separation date on their birth record $(n=289)$; or they died before 29 days of age $(n=2954)$. A total of 1121 440 children were included in this analysis (Table 1).

\section{Analysis variables}

Our main outcome was pediatric potentially avoidable hospitalizations, as defined by Andersen et al. [12]. We also report ambulatory care sensitive and non-avoidable hospitalizations [12]. We used the primary diagnosis to identify avoidable, ambulatory care sensitive or nonavoidable hospitalizations (Additional file 1: Table S1). Admissions occurring before children were 29 days old were excluded. Hospitalizations for vaccine preventable diseases were classified as avoidable if the child's age was greater than or equal to the recommended immunisation age for each condition in NSW [23]. Admissions for which the emergency status was coded as 'planned' were excluded from the count of avoidable hospitalizations, except for dental conditions, because most planned admissions are unlikely to be avoidable.

The following individual- and area-level covariates were in the hospital data: Aboriginality; age; sex; low birth weight $(<2500 \mathrm{~g})$ and/or prematurity ( $<37$ weeks gestation); private health insurance/patient status; remoteness of residence, measured by the Accessibility/Remoteness Index of Australia Plus (ARIA+) [24]; and area socioeconomic disadvantage, measured by the Australian Bureau of Statistics Socioeconomic Indexes for Areas (SEIFA) [25]. The child's Aboriginality recorded in the hospital data is based on the response to the question 'Is this child of Aboriginal or Torres Strait Islander origin?, which is asked directly of the mother at birth, and of a parent or guardian at admission for children aged less than 15 years. Although the number of Aboriginal people identified in hospital data increases with the use of multiple record algorithms [26-28], we assigned Aboriginality from the birth record to avoid introducing misclassification bias whereby more frequently hospitalized children have more opportunity to be recorded as Aboriginal, either correctly or in error. For the same reason, we assigned other variables from the birth admission. We calculated the child's age on admission as the difference between their dates of birth and admission.

\section{Data analysis}

We calculated person-years of follow-up for each child from the date they were 29 days old until 31 December 2013, or their date of death. We estimated admission rates (ARs) per 1000 person-years by dividing the number of admissions by the person-years accumulated, and multiplying by 1000 . We calculated $95 \%$ confidence intervals (CIs) assuming a Poisson distribution of events. Rate differences were calculated by subtracting the AR for nonAboriginal children from the AR for Aboriginal children. Aboriginal to non-Aboriginal admission rate ratios (ARRs) for each outcome and age group were calculated by dividing the Aboriginal AR by the non-Aboriginal AR. We calculated the proportion of avoidable hospital admissions that occurred outside of standard general medical practice hours (i.e. 08:00-18:00) [29].

To account for differences in age and sex, negative binomial models were used to estimate adjusted ARRs for Aboriginal to non-Aboriginal children for each outcome and condition, modeling the number of hospitalizations as an outcome (using a log link), and including terms for age (in two year age groups), sex and Aboriginal status, with the log of the person-years of follow-up as an offset (Model 1). To account for clustering within geographic statistical local areas (henceforth, 'areas'), a random intercept term was added to the model, which allowed the baseline admission rate to vary between areas, creating a multi-level model (Model 2). In the multilevel model, we then explored whether any of the inequality in study outcomes reflected differences between Aboriginal and non-Aboriginal children in terms of other measured covariates (Model 3). To test whether the effect of covariates on each outcome were the same for Aboriginal and non-Aboriginal children, we tested interaction terms between Aboriginal status and each covariate in 
Table 1 Characteristics and person years of follow-up time (2000-2013) for Aboriginal and non-Aboriginal children in a population cohort born between July 2000 and December 2012 in New South Wales, Australia

\begin{tabular}{|c|c|c|c|c|c|c|}
\hline & \multicolumn{3}{|c|}{ Non-Aboriginal } & \multicolumn{3}{|c|}{ Aboriginal } \\
\hline & $\bar{N}$ & $\%$ & Person years & $\bar{N}$ & $\%$ & Person years \\
\hline$\overline{\text { Total }}$ & $1,085,831$ & 100 & $7,681,406$ & 35,609 & 100 & 223,190 \\
\hline \multicolumn{7}{|l|}{ Birth year } \\
\hline Jul 2000-Dec 2004 & 367,542 & 34 & $4,125,434$ & 9,047 & 25 & 100,296 \\
\hline Jan 2005-Dec 2008 & 353,945 & 33 & $2,466,933$ & 11,607 & 33 & 79,332 \\
\hline Jan 2009-Dec 2012 & 364,344 & 34 & $1,089,040$ & 14,955 & 42 & 43,562 \\
\hline \multicolumn{7}{|l|}{ Contribution of follow-up to age group ${ }^{a}$} \\
\hline Less than 2 years & - & - & $2,123,515$ & - & - & 68,971 \\
\hline $2-4$ years & - & - & $1,802,906$ & - & - & 55,189 \\
\hline 4-6 years & - & - & $1,440,318$ & - & - & 41,123 \\
\hline $6-8$ years & - & - & $1,081,702$ & - & - & 28,451 \\
\hline $8-10$ years & - & - & 736,009 & - & - & 18,066 \\
\hline $10-12$ years & - & - & 406,279 & - & - & 9,431 \\
\hline $12-13$ years & - & - & 90,678 & - & - & 1,959 \\
\hline \multicolumn{7}{|l|}{ Sex } \\
\hline Female & 527,500 & 49 & $3,729,845$ & 17,251 & 48 & 108,591 \\
\hline Male & 558,331 & 51 & $3,951,561$ & 18,358 & 52 & 114,599 \\
\hline \multicolumn{7}{|l|}{ Low birth weight and/or premature birth } \\
\hline No & $1,017,508$ & 94 & $7,212,029$ & 32,039 & 90 & 201,599 \\
\hline Yes & 68,323 & 6 & 469,377 & 3,570 & 10 & 21,591 \\
\hline \multicolumn{7}{|l|}{ Private patient and/or health insurance } \\
\hline No & 702,362 & 65 & $5,049,008$ & 34,531 & 97 & 217,477 \\
\hline Yes & 383,469 & 35 & $2,632,399$ & 1,078 & 3 & 5,713 \\
\hline \multicolumn{7}{|l|}{ Geographical remoteness } \\
\hline Major city & 730,967 & 67 & $5,105,713$ & 10,238 & 29 & 64,754 \\
\hline Inner regional & 262,887 & 24 & $1,899,768$ & 13,231 & 37 & 79,583 \\
\hline Outer regional & 84,425 & 8 & 617,719 & 8,837 & 25 & 56,053 \\
\hline Remote/Nery remote & 7,552 & 1 & 58,205 & 3,303 & 9 & 22,800 \\
\hline \multicolumn{7}{|l|}{ Area-level socio-economic disadvantage ${ }^{b}$} \\
\hline First quintile (Most disadvantaged) & 199,716 & 18 & $1,443,310$ & 16,719 & 47 & 107,615 \\
\hline Second quintile & 235,069 & 22 & $1,669,550$ & 9,746 & 27 & 59,739 \\
\hline Third quintile & 219,196 & 20 & $1,560,849$ & 6,210 & 17 & 37,857 \\
\hline Fourth quintile & 225,527 & 21 & $1,569,176$ & 2,344 & 7 & 14,415 \\
\hline Fifth quintile (Least disadvantaged) & 206,323 & 19 & $1,438,522$ & 590 & 2 & 3,564 \\
\hline
\end{tabular}

${ }^{a}$ Children contribute person years of follow-up from the date they are 29 days old until their death or the end of the study period (December 31,2013 ). Many of

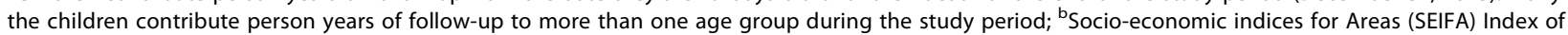
Relative Socio-Economic Advantage and Disadvantage based on the child's statistical local area of residence at birth

multilevel models adjusted for age, sex, and variation in rates between areas (by including a random intercept term for areas).

We used SAS 9.3 [30], MLwiN 2.25 [31], and R 2.15.0 for analyses [32]. Multilevel modeling in MLwiN used generalized least squares (IGLS) estimation and a 2nd order PQL approximation.

\section{Results}

We identified 365386 potentially avoidable hospitalizations among the 1121440 children born between 1 July 2000 and 31 December 2012, who were followed from birth until 31 December 2013 (Additional file 1: Table S2). Of these, 243643 hospitalizations were considered ambulatory care sensitive. The avoidable hospitalization rate was 90.1 per 
1000 person-years (95 \% CI, 88.9-91.4) in Aboriginal children compared with 44.9 per 1000 person-years $(95 \%$ CI, 44.8-45.1) in non-Aboriginal children (Additional file 1: Table S2). The ambulatory care sensitive hospitalization rate was 56.7 (95\% CI, 55.7-57.7) and 30.1 (95\% CI, 29.9-30.2) per 1000 person-years in Aboriginal and non-Aboriginal children, respectively. Of the ambulatory care sensitive hospitalizations, $56 \%$ and $57 \%$ of admissions occurred outside standard general practice hours for Aboriginal and non-Aboriginal children, respectively. The non-avoidable hospitalization rate was $10.1(95 \% \mathrm{CI}$, 9.6-10.5) and 9.6 (95\% CI, 9.6-9.7) per 1000 person years in Aboriginal and non-Aboriginal children.

The five most common causes of avoidable hospitalization among Aboriginal children in the cohort were acute bronchiolitis (AR, 20.3; 95 \% CI, 19.7-20.9), gastroenteritis (AR, 12.2; 95 \% CI, 11.7-12.7), asthma (AR, 10.8; $95 \%$ CI, 10.3-11.2), dental conditions (AR, 9.4; $95 \%$ CI, 9.0-9.8), and acute upper respiratory tract infections (URTIs) (AR, 9.3; 8.9-9.7) (Fig. 1). Four of the five most common causes were the same for non-Aboriginal children, but with lower rates: gastroenteritis (AR, 7.8; $95 \% \mathrm{CI}, 7.8-7.9$ ), asthma (AR, 7.3; $95 \%$ CI, 7.2-7.4), acute bronchiolitis (AR, 6.5; $95 \%$ CI, 6.5-6.6), acute URTIs (AR, 4.6; 95 \% CI 4.6-4.7) and viral infection of unspecified site (AR, 3.8; $95 \%$ CI $3.7-$ 3.8) (Fig. 1). The conditions with the greatest Aboriginal to non-Aboriginal rate difference were acute bronchiolitis (RD, 13.8), dental (RD, 5.7), acute URTIs (RD, 4.7), gastroenteritis (RD, 4.4) and skin infections (4.2) (Additional file 1: Table S2).

Potentially avoidable
Ambulatory Care Sensitive
Gastroenteritis
Asthma
Dental
Acute upper respiratory infection
Skin infection
Bacterial/unspecified pneumonia
Otitis media
Vaccine preventable diseases
Dermatitis/eczema
Gastro oesophageal reflux
Constipation
Urinary tract infection ( $>=5$ yrs)
Nutritional deficiency
Acute rheumatic fever
Bronchiectasis
Chronic rheumatic heart disease
Other avoidable
Acute bronchiolitis
Viral infection of unspecified site
Croup, acute laryngitis, tracheitis
Febrile convulsions
Viral pneumonia
Viral/other/unspecified meningitis
Osteomyelitis
Meningococcal disease
Bacterial meningitis
Tuberculosis
Non-avoidable
Urinary tract infection ( $<5$ years)
Epilepsy/status epilepticus
Neoplasm (malignant or not)
Inguinal hernia
Abdominal/pelvic pain
Acute appendicitis
Coaguation defects
Chemotherapy
Type 1 diabetes
Cystic fibrosis
Immune disorders

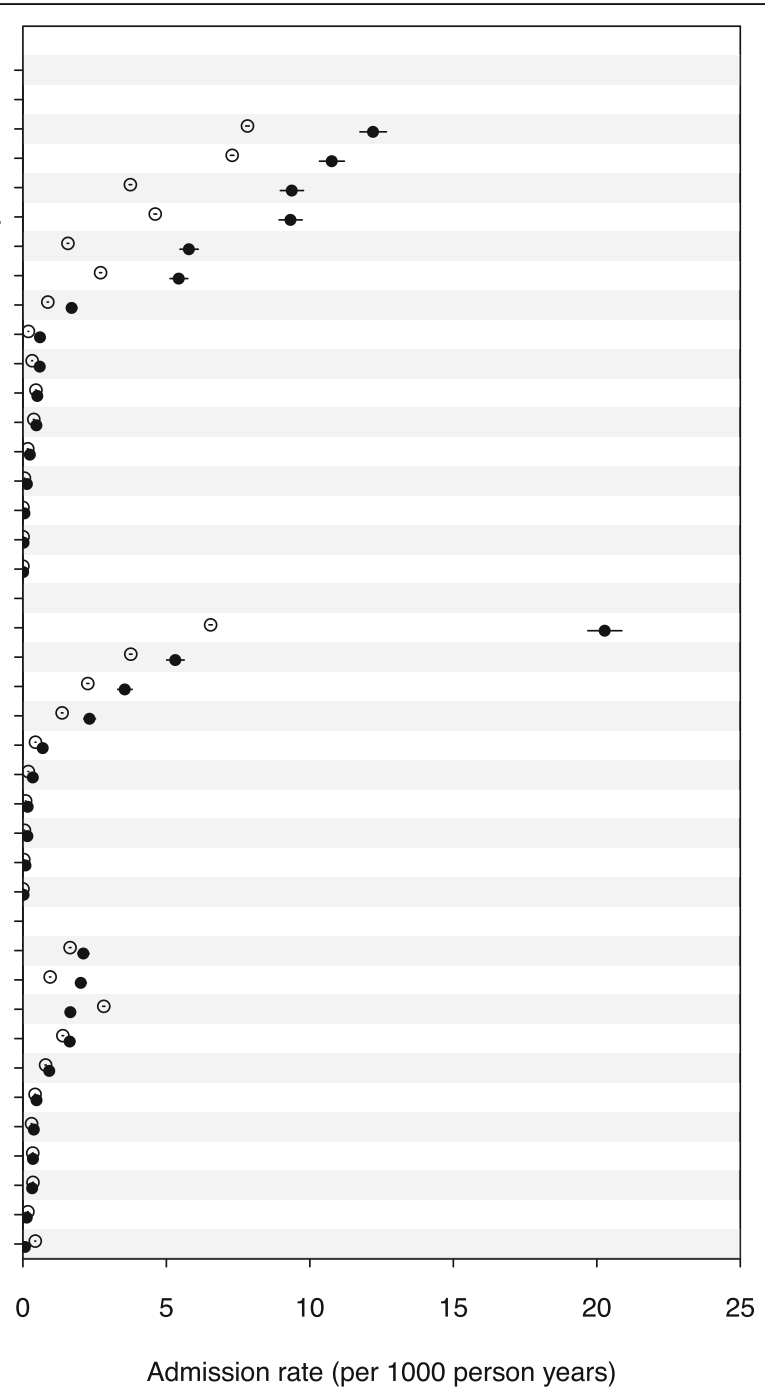

Fig. 1 Title: Admission rates for potentially avoidable and non-avoidable hospitalizations (2000-2013) in a population cohort of Aboriginal and non-Aboriginal children born 2000-2012, New South Wales, Australia. Legend: closed circles, Aboriginal; open circles, non-Aboriginal; Error bars (through circles) are $95 \%$ confidence intervals. Sorted by Aboriginal admission rates in descending order. Admission rates, rate differences, rate ratios and $95 \%$ confidence intervals are shown in Additional file 1: Table S2 
For Aboriginal and non-Aboriginal children, avoidable hospitalization rates were highest among those aged less than two years (179.9 and 85.7 per 1000 person-years, respectively) and decreased to less than 10 per 1000 person-years among children aged 12 to $<14$ years (Fig. 2). Among children less than two years of age, Aboriginal children were 1.9 times more likely to be admitted for an avoidable hospitalization than non-Aboriginal children, and the rate difference was 94.1 per 1000 person-years (Fig. 2, Table 2). The rate difference between Aboriginal and non-Aboriginal children declined to 5.3 per 1000 person-years by 12 to $<14$ years of age.

Aboriginal children had higher avoidable hospitalization rates across all categories of sex, low birth weight/prematurity, private health insurance/patient status and remoteness or disadvantage of the area where children started life (Fig. 3). In particular, the relative difference in avoidable hospitalizations between those living in remote areas versus major cities was greater for Aboriginal versus nonAboriginal children; compared with non-Aboriginal children living in major cities (ARR, 1.0; reference group), Aboriginal children living in remote areas and major cities were 2.2 (95\% CI, 1.9-2.6) and 1.5 (95\% CI, 1.4-1.5) times more likely to be admitted for an avoidable hospitalization, respectively (Fig. 4). In contrast, nonAboriginal children living in remote areas were 1.1 (95\% CI, 1.0-1.3) times more likely to be admitted for an avoidable hospitalization than non-Aboriginal children living in major cities.

After adjusting for differences in age and sex (Model 1), Aboriginal children were 1.7 times as likely to have an avoidable hospitalization as non-Aboriginal children in the cohort (Table 3). When variation in admission rates between areas was also accounted for (Model 2), the Aboriginal to non-Aboriginal admission rate ratio for avoidable hospitalizations was 1.6 (95 \% CI, 1.6-1.6). After accounting for differences in individual- and area-level characteristics (Model 3), the Aboriginal to non-Aboriginal admission rate ratio was 1.6 (95\% CI, 1.6-1.7). The magnitude of the inequality was similar for the subset of ambulatory care sensitive hospitalizations, after adjustment for age and sex (ARR, 1.7; 95 \% CI, 1.71.8 ), and after inclusion of random intercept and adjustment for all covariates (ARR,1.6; 95 \% CI, 1.6-1.6) (Table 3). In contrast, Aboriginal children were marginally less likely to be admitted for a non-avoidable hospitalization than non-Aboriginal children (Table 3; ARR, 0.9; 95 \% C, 0.81.0) after adjustment for age, sex and variation in admission rates between areas.

\section{Discussion}

We found that avoidable hospitalization rates were almost double in Aboriginal compared with non-Aboriginal children less than two years of age, and the absolute difference in rates was 94 per 1000 person-years. Although the absolute and relative inequalities were present across all ages, the absolute difference in rates between Aboriginal and non-Aboriginal children declined to 5 per 1000 person-years by 12 to $<14$ years of age. Respiratory and infectious conditions were the most common reasons for avoidable hospitalizations in all children, although Aboriginal children were admitted more frequently for all conditions. We also found that the impact of living in more remote and disadvantaged areas on a child's risk of avoidable hospitalization was greater for Aboriginal children.

To our knowledge, this is the first Australian study to reveal that avoidable hospitalizations are highest in children in the first two years of life and decrease among older children, consistent with findings in New Zealand [18].
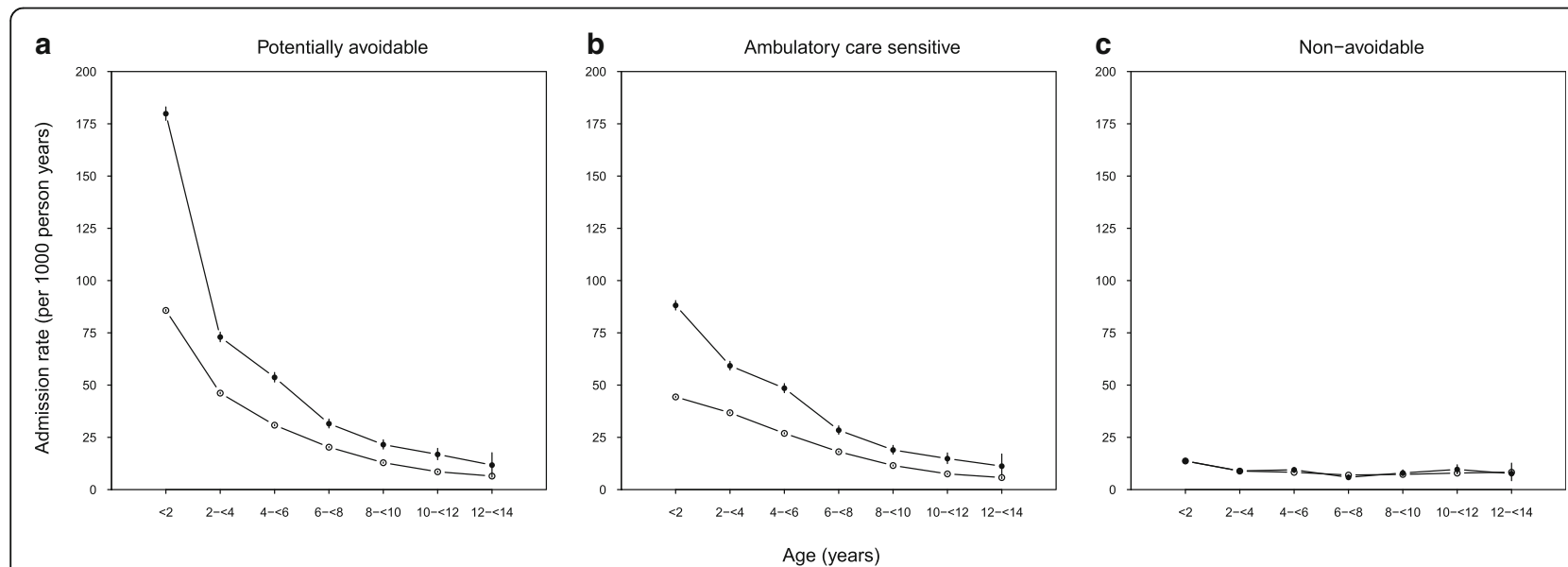

Fig. 2 Title: Age-specific admission rates for potentially avoidable, ambulatory care sensitive and non-avoidable hospitalizations (2000-2013) in a population cohort of Aboriginal and non-Aboriginal children born 2000-2012, New South Wales, Australia. Legend: closed circles, Aboriginal; open circles, non-Aboriginal. Error bars (through circles) are $95 \%$ confidence intervals 
Table 2 Age-specific Aboriginal to non-Aboriginal rate differences and rate ratios for potentially avoidable, ambulatory care sensitive and non-avoidable hospitalisations (2000-2013) in a population cohort of Aboriginal and non-Aboriginal children born between July 2000 and December 2012 in New South Wales, Australia

\begin{tabular}{|c|c|c|c|c|c|c|c|c|c|}
\hline \multirow{3}{*}{$\begin{array}{l}\text { Age group } \\
0-<2 \text { years }\end{array}$} & \multicolumn{3}{|l|}{ Potentially avoidable } & \multicolumn{3}{|c|}{ Ambulatory care sensitive } & \multicolumn{3}{|c|}{ Non-avoidable } \\
\hline & \multirow{2}{*}{$\begin{array}{l}\text { Rate difference (RD) } \\
94.1\end{array}$} & \multicolumn{2}{|c|}{ Rate ratio (RR) $(95 \%$ Cl) } & \multirow{2}{*}{$\frac{\mathrm{RD}}{43.79}$} & \multicolumn{2}{|c|}{ RR $(95 \% \mathrm{Cl})$} & \multirow{2}{*}{$\frac{\mathrm{RD}}{-<0.1}$} & \multicolumn{2}{|c|}{ RR $(95 \% \mathrm{Cl})$} \\
\hline & & 1.9 & $(1.8-1.9)$ & & 1.9 & $(1.8-1.9)$ & & 0.8 & $(0.7-0.9)$ \\
\hline $2-<4$ years & 26.8 & 1.5 & $(1.5-1.6)$ & 22.49 & 1.6 & $(1.5-1.6)$ & $<0.1$ & 0.8 & $(0.7-0.9)$ \\
\hline $4-<6$ years & 22.9 & 1.7 & $(1.6-1.8)$ & 21.58 & 1.8 & $(1.7-1.9)$ & 1.2 & 1.0 & $(0.7-1.4)$ \\
\hline $6-<8$ years & 11.3 & 1.5 & $(1.4-1.6)$ & 10.31 & 1.6 & $(1.4-1.7)$ & -1.1 & 0.9 & $(0.6-1.2)$ \\
\hline $8-<10$ years & 8.7 & 1.7 & $(1.5-1.9)$ & 7.45 & 1.6 & $(1.5-1.8)$ & 0.7 & 1.1 & $(0.9-1.3)$ \\
\hline $10-<12$ years & 8.3 & 2.0 & $(1.7-2.3)$ & 7.32 & 2.0 & $(1.6-2.3)$ & 1.7 & 1.2 & $(0.9-1.6)$ \\
\hline $12-<14$ years & 5.3 & 1.8 & $(1.2-2.8)$ & 5.46 & 2.0 & $(1.3-3.0)$ & -0.7 & 1.0 & $(0.6-1.6)$ \\
\hline
\end{tabular}

$C l$ confidence interval, $R D$ rate difference, $R R$ rate ratio

For the first time, we demonstrated that absolute differences in avoidable hospitalizations between Aboriginal and non-Aboriginal children were greatest in children less than two years, while the magnitude of the relative inequality was similar across age groups. In most contexts, both the absolute and relative differences between two groups matter [33]. That the relative inequality is similar across age groups suggests there is a general problem that requires a systemic approach. On the other hand, the greater absolute differences in avoidable hospitalizations between Aboriginal and non-Aboriginal children less than two years of age indicate there may be scope to reduce avoidable hospitalizations via targeted prevention and early intervention measures that reduce disease burden and improve access to treatment for common childhood conditions.

Respiratory and infectious conditions were the most common reasons for avoidable hospitalization among all children in the cohort, with Aboriginal children more likely to be admitted for all conditions. These findings are consistent with other Australian data on common conditions resulting in pediatric emergency department presentations [34] and higher hospitalization rates for respiratory diseases [35-39] and gastroenteritis [38, 40-42] among Aboriginal children in Western Australia. Although we were unable to ascertain the burden of these conditions outside of the

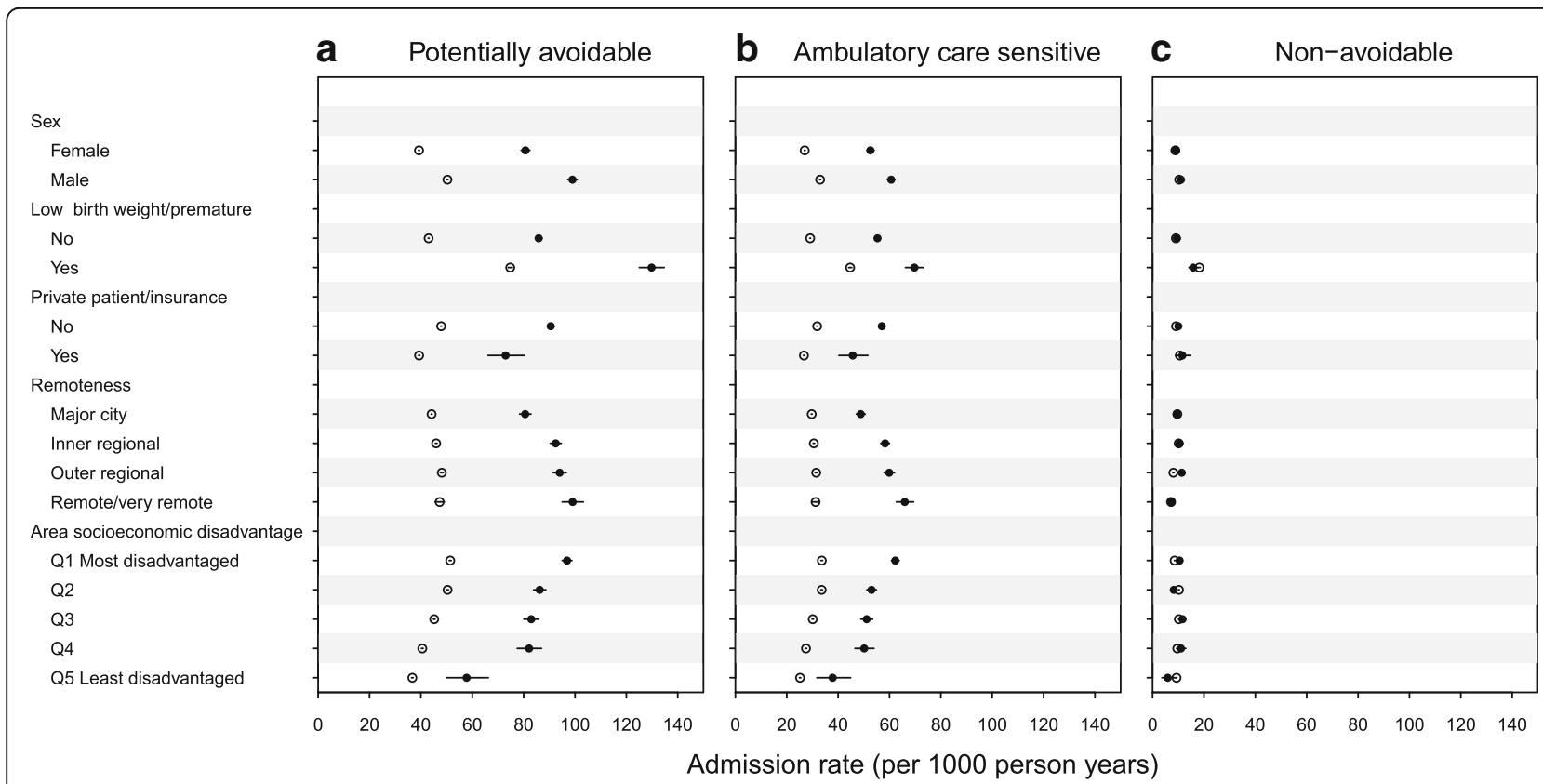

Fig. 3 Title: Admission rates for (a) potentially avoidable, (b) ambulatory care sensitive and (c) non-avoidable hospitalizations (2000-2013) by individual- and area-level characteristics in a population cohort of Aboriginal and non-Aboriginal children born 2000-2012, New South Wales, Australia. Legend: closed circles, Aboriginal; open circles, non-Aboriginal. Error bars (through circles) are $95 \%$ confidence intervals 


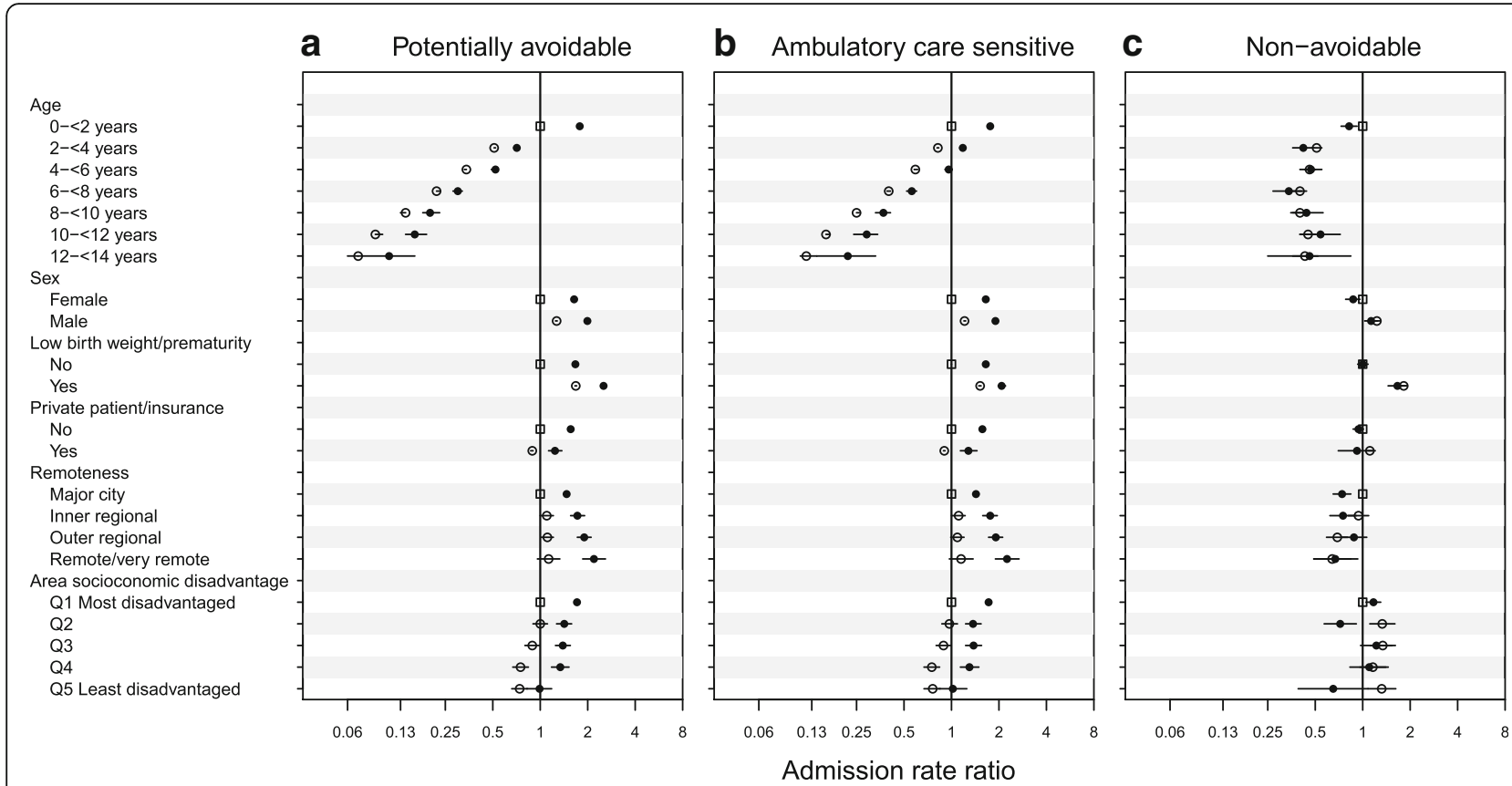

Fig. 4 Title: Admission rate ratios for (a) potentially avoidable, (b) ambulatory care sensitive, and (c) non-avoidable hospitalizations for interactions between individual- and area-level characteristics and Aboriginal status from multilevel negative binomial models with a random intercept for Statistical Local Area, adjusted for age and sex. Rate ratios are relative to the reference group. Legend: closed circles, Aboriginal; open circles, non-Aboriginal; open square, non-Aboriginal reference group. Error bars (through symbols) are $95 \%$ confidence intervals

hospital setting, other studies have previously reported a high burden of respiratory diseases [43-46], skin infections [47] and otitis media [48-50] in Aboriginal children, particularly in remote communities. Moreover, some important exposures associated with respiratory and infectious conditions, such as smoking $[51,52]$ and poor housing conditions [53], are known to be common in Aboriginal families [54-56] and associated with poverty. Dental conditions were also a common cause of avoidable hospitalization for Aboriginal children. Previous studies have also documented poor dental health in Aboriginal communities [57-59], as well as higher rates of hospitalization for dental conditions among Aboriginal children in Western Australia [60, 61].

The remoteness or disadvantage of the area where a child lives has previously been associated with avoidable hospitalizations in children in the Australian state of

Table 3 Aboriginal to non-Aboriginal admission rate ratios from multilevel models for potentially avoidable, ambulatory care sensitive and non-avoidable hospitalisations (July 2000 to December 2013) in a population cohort of children born between July 2000 and December 2012 in New South Wales, Australia

\begin{tabular}{|c|c|c|c|c|}
\hline Model & Variables and random effects added to the model: & Aboriginal to non-Aboriginal Rate Ratio & \multicolumn{2}{|c|}{$95 \%$ confidence interval } \\
\hline \multicolumn{5}{|c|}{ Potentially avoidable hospitalisations } \\
\hline 1 & Age and sex & 1.73 & 1.71 & 1.75 \\
\hline 2 & Model $1+$ random intercept for area & 1.60 & 1.58 & 1.62 \\
\hline 3 & Model $2+$ individual $^{\mathrm{a}}$ - and area $^{\mathrm{b}}$-level characteristics & 1.60 & 1.58 & 1.61 \\
\hline \multicolumn{5}{|c|}{ Ambulatory care sensitive hospitalisations } \\
\hline 1 & Age and sex & 1.74 & 1.72 & 1.77 \\
\hline 2 & Model $1+$ random intercept for area & 1.60 & 1.58 & 1.62 \\
\hline 3 & Model $2+$ individual $^{\mathrm{a}}$ - and area $^{\mathrm{b}}$-level characteristics & 1.57 & 1.55 & 1.59 \\
\hline \multicolumn{5}{|c|}{ Non-avoidable hospitalisations } \\
\hline 1 & Age and sex & 0.89 & 0.81 & 0.97 \\
\hline 2 & Model $1+$ random intercept for area & 0.90 & 0.82 & 0.97 \\
\hline 3 & Model $2+$ individual $^{\mathrm{a}}$ - and area $^{\mathrm{b}}$-level characteristics & 1.03 & 0.96 & 1.10 \\
\hline
\end{tabular}

${ }^{a}$ Low birth weight/prematurity and private health insurance/patient status; ${ }^{\mathrm{b}}$ geographical remoteness and area socio-economic disadvantage 
Victoria [13, 14] and New Zealand [18]. What this study shows is that living in more remote or disadvantaged areas has a greater impact on a child's risk of avoidable hospitalization if they are Aboriginal. Aboriginal families living in remote and disadvantaged areas experience a disproportionate burden of the determinants of poor child health (e.g. overcrowded housing [54]). Barriers to accessing primary care for Aboriginal families - including some that may disproportionately impact on those living in remote and disadvantaged areas - have previously been identified, including: the physical availability of health services (which are clustered in major cities and more advantaged areas), transport, flexible service delivery, affordability, and the cultural acceptability and appropriateness of health services [62]. Health literacy, physician behaviour and hospital admission practices may also impact on whether a child is admitted to hospital.

Because Australia's universal health insurance scheme (Medicare) covers the cost of necessary health care provided to public patients admitted to public hospitals [22], costs associated with hospitalisation should not have been a determinant of rates of avoidable hospitalisation in this study. However, families may incur costs for seeking GP care because Australian GPs have the option to charge patients more than the Medicare Benefits Schedule fee. During the study period, NSW patients paid an out-of-pocket 'gap' payment for $14-24 \%$ of all GP visits [63]. Therefore, costs associated with GP services may deter some families from seeking primary health care for their children in a timely manner.

Use of population data in this study conferred the advantage of a large cohort; this enabled us to reliably quantify the magnitude of the inequality in avoidable hospitalizations between Aboriginal and non-Aboriginal children in narrow age bands for the first time, which is important for guiding policy. Importantly, it has also made visible the health experience of Aboriginal children, a small and disadvantaged sub-population. Other strengths of the study include the length of follow-up for children born earlier in the study period and minimal loss to follow-up (children account for a small proportion of the $3 \%$ of people who migrate outside of NSW each year [64, 65]).

Potential limitations of the outcome measure must be considered. The extent to which the avoidable hospitalizations identified in this study were truly avoidable is unknown. Recent research suggests that socio-demographic and health factors explain more of the geographic variation in adult avoidable hospitalizations than general practitioner supply [66], and our main outcome measure was not focused on primary care as the sole strategy for reducing avoidable hospitalizations. However, we found similar inequalities for avoidable hospitalizations and the subset of ambulatory care sensitive hospitalizations. Despite living in the same area, Aboriginal and non-Aboriginal children may not realise equal access to available primary care services, for reasons including transport difficulties and cultural barriers [62]. In this study, more than half the ambulatory care sensitive hospitalizations occurred outside office hours. From our data, we were unable to determine whether these admissions were for severe and rapid onset illness that would have resulted in hospitalization under any circumstances, or whether improved access to primary care in the days and hours prior to hospitalization might have prevented some of these hospitalizations.

A limitation of using routinely collected hospital data is the under-recording of Aboriginal status [26, 67-69]. These errors are not randomly distributed across hospitals and areas; past audits have shown Aboriginal status has been recorded more accurately in remote areas and that recording of Aboriginal status has improved over time $[68,69]$. We aimed to minimize bias introduced in this study by deriving both the numerator and the denominator from the hospital data, rather than deriving the denominator from census data. Another shortcoming is the limited set of covariates available in the data. Private health insurance/patient status was the only individual-level indicator of socioeconomic advantage in the data, and only $3 \%$ of Aboriginal children had private health insurance or were admitted as a private patient compared with $35 \%$ of nonAboriginal children. The higher proportion of Aboriginal children with low birth weight and/or prematurity in this cohort likely reflects a greater burden of socioeconomic disadvantage among Aboriginal children, but measures such as household income and parent education level were not available. As such, our modeling shows the effect of Aboriginality combined with other unmeasured covariates.

\section{Conclusions}

In an equitable world, there should be no difference in avoidable hospitalizations between Aboriginal and nonAboriginal children. We observed substantial inequalities in these hospitalizations between Aboriginal and nonAboriginal children regardless of where they lived, but particularly among very young children. An important question is: How can we close this gap? Broad policy measures that aim to reduce inequities in the circumstances in which children grow and develop (e.g. better quality and affordable housing) may impact on the incidence of common childhood conditions in Aboriginal children, including hospitalization for these conditions $[12,70]$. Increased access to early intervention in primary care, particularly for young Aboriginal children, and those living in remote and disadvantaged areas, may also impact on avoidable hospitalizations. Finally, this study provides a novel source of baseline population data to inform the future impact of policies and interventions on existing inequalities. 


\section{Additional file}

Additional file 1: Table S1. (ICD-10-AM codes) and Table S2. (Potentially avoidable, ambulatory care sensitive and non-avoidable hospitalisation admission rates). Table S1. title "List of ICD-10-AM codes used to identify potentially avoidable, ambulatory care sensitive and non-avoidable hospitalisations (adapted from Andersen et al., 2012)", and Table S2. title "Potentially avoidable, ambulatory care sensitive and non-avoidable hospitalisation admission rates (2000-2013) in a population cohort of Aboriginal and non-Aboriginal children born between July 2000 and December 2012 in New South Wales, Australia". (DOCX 61 kb)

\section{Abbreviations}

ARRs: Admission rate ratios; ARs: Admission rates; Cls: Confidence intervals; ICD-10-AM: International Statistical Classification of Diseases and Related Problems 10th Revision; NSW: New South Wales

\section{Acknowledgements}

We acknowledge the New South Wales (NSW) Centre for Health Record Linkage for conducting the probabilistic linkage of records, and the NSW Ministry of Health and the NSW Register of Births, Deaths and Marriages for allowing access to the data. Although the death registration data in this study is de-identified, we acknowledge the grief that reference to these deaths may cause the family and friends that have lost a child during the study period. The authors acknowledge the following additional contributions: project coordination and data management for the IHOPE study from Deborah Randall; data management for the IHOPE study in 2015 from Holger Möller; and $R$ code for the figures from Dr Daniel Falster.

\section{Funding}

This work was supported by the National Health and Medical Research Council of Australia [grant numbers 573113 to L.J, S.E. and S.L., 1016475 to K.F., 573122 to L.J., S.E. and K.F., 1042717 to E.B., 570120 to J.L., 1056888 to J.L.]. AL is funded by the UK Medical Research Council (MC_UU_12017/13) and the Chief Scientist Office of the Scottish Government Health Directorate (SPHSU13). The funding bodies had no role in the design of the study, acquisition of, analysis, and interpretation of data, and in writing the manuscript.

\section{Availability of data and materials}

The datasets supporting the conclusions of this article are available from the Ministry of Health and the Register of Births, Deaths and Marriages, New South Wales (NSW), Australia. The NSW Centre for Health Record Linkage linked the datasets for this study. These data are available to researchers on request and subject to approval from the relevant data custodians and ethics committees, as outlined on the NSW Centre for Health Record Linkage website (http://www.cherel.org.au/).

\section{Authors' contributions}

$\sqcup J$ and KF had full access to all of the data in the study and take responsibility for the integrity of the data and the accuracy of the data analysis. $L J$ and SE contributed to the conception and design of the Indigenous Health Outcomes Patient Evaluation (IHOPE) study. LJ initiated the IHOPE study and supervised all analyses. KF designed and conducted the statistical analysis for this sub-study, and drafted the manuscript, with input from all authors. SL, MF and AL contributed statistical expertise for this substudy. All authors contributed to the interpretation of findings, providing feedback on drafts of the manuscript and approved the final draft.

\section{Competing interests}

The authors declare that they have no competing interests.

\section{Consent for publication}

No applicable.

\section{Ethics approval and consent to participate}

Ethics approval was obtained from the NSW Population and Health Services Research Ethics Committee (Ref no. 2009/03/141), Aboriginal Health and Medical Research Council of NSW Ethics Committee (Ref no. 684/09), and the University of Western Sydney (Ref no. H7304), and Australian National University Human Research Ethics Committees (Ref no. 2015/506). For this statewide population data linkage study, the need to obtain consent from individuals to participate in the study was waived by the reviewing ethics committees. Approval to link and use these data was obtained from the relevant data custodians (NSW Ministry of Health and NSW Register of Births, Deaths and Marriages) prior to seeking ethical approval.

\section{Author details}

${ }^{1}$ National Centre for Epidemiology and Population Health, Australian National University, Canberra, Australia. ${ }^{2}$ The Sax Institute, Sydney, Australia. ${ }^{3}$ Centre for Big Data Research in Health, University of New South Wales, Sydney, Australia. ${ }^{4}$ Centre for Health Research, School of Medicine, University of Western Sydney, Campbelltown, Australia. ${ }^{5}$ School of Public Health University of Adelaide, Adelaide, Australia. 'Sydney Children's Hospitals Network, Sydney, Australia. 'School of Women and Children's Health, Faculty of Medicine, University of New South Wales, Sydney, Australia. ${ }^{8}$ Baker IDI Heart and Diabetes Institute, Melbourne, Australia. ${ }^{9} \mathrm{MRC} / \mathrm{CSO}$ Social and Public Health Sciences Unit, University of Glasgow, Glasgow, Scotland.

Received: 30 March 2016 Accepted: 4 October 2016

Published online: 21 October 2016

\section{References}

1. Australian Health Ministers' Advisory Council. Aboriginal and Torres Strait Islander Health Performance Framework 2014 Report. Canberra: AHMAC; 2014

2. Australian Institute of Health and Welfare. National Partnership Agreement on Indigenous Early Childhood Development: second annual report on health performance indicators. Cat. no. IHW 151. Canberra: AlHW; 2015.

3. Hilder L, Zhichao Z, Parker M, Jahan S, Chambers GM. Australia's mothers and babies 2012. Perinatal statistics series no. 30. Cat no. PER 69. Canberra: Australian Institute of Health and Welfare; 2014.

4. Australian Curriculum Assessment and Reporting Authority. NAPLAN Achievement in reading, persuasive writing, language conventions and numeracy: National Report for 2011. Sydney: Australian Curriculum, Assessment and Reporting Authority; 2011.

5. Australian Government. A Snapshot of Early Childhood Development in Australia 2012 - Australian Early Development Index (AEDI) National Report. Canberra: Australian Government; 2012.

6. Australian Government. Closing the gap: Prime Minister's report 2014 Canberra: Australian Government; 2014

7. Australian Institute of Health and Welfare. The health and welfare of Australia's Aboriginal and Torres Strait Islander people: an overview 2011. Cat. no. IHW 42. Canberra: AlHW; 2011

8. Bowes J, Grace R. Review of early childhood parenting, education and health intervention programs for Indigenous children and families in Australia, Produced for the Closing the Gap Clearinghouse, Issue paper no. 8. Canberra: Australian Institute of Health and Welfare \& Melbourne: Australian Institute of Family Studies; 2014.

9. Rutstein DD, Berenberg W, Chalmers TC, Child CG, Fishman AP, Perrin EB, Feldman JJ, Leaverton PE, Lane JM, Sencer DJ, et al. Measuring the Quality of Medical Care. N Engl J Med. 1976;294:582-8.

10. Australian Institute of Health and Welfare. National Healthcare Agreement: PI 22-Selected potentially preventable hospitalisations, 2012. 2012 http://meteor.aihw.gov.au/content/index.phtml/itemld/443687. Accessed 14 May 2013

11. Agency for Healthcare Research and Quality. AHRQ Pediatric Quality Indicators Overview. AHRQ Quality Indicators. Rockville, Md: US Department of Health and Human Services, Agency for Healthcare Research and Quality; 2006.

12. Anderson P, Craig E, Jackson G, Jackson C. Developing a tool to monitor potentially avoidable and ambulatory care sensitive hospitalisations in New Zealand children. N Z Med J. 2012;125:25-37.

13. Ansari Z, Haider SI, Ansari H, de Gooyer T, Sindall C. Patient characteristics associated with hospitalisations for ambulatory care sensitive conditions in Victoria, Australia. BMC Health Serv Res. 2012;12:475.

14. Butler DC, Thurecht L, Brown L, Konings P. Social exclusion, deprivation and child health: a spatial analysis of ambulatory care sensitive conditions in children aged 0-4 years in Victoria, Australia. Soc Sci Med. 2013:94:9-16.

15. Harrold TC, Randall DA, Falster MO, Lujic S, Jorm LR. The contribution of geography to disparities in preventable hospitalisations between indigenous and non-indigenous Australians. PLoS One. 2014;9:e97892.

16. Li SQ, Gray NJ, Guthridge SL, Pircher SLM. Avoidable hospitalisation in Aboriginal and non-Aboriginal people in the Northern Territory. Med J Aust. 2009;190:532-6. 
17. Stamp KM, Duckett SJ, Fisher DA. Hospital use for potentially preventable conditions in Aboriginal and Torres Strait Islander and other Australian populations. Aust N Z J Public Health. 1998;22:673-8.

18. Craig E, Anderson P, Jackson G, Jackson C. Measuring potentially avoidable and ambulatory care sensitive hospitalisations in New Zealand children using a newly developed tool. N Z Med J. 2012;125:38-50.

19. National Centre for Classification in Health. International Statistical Classification of Diseases and Related Health Problems, 10th Revision, Australian Modification (ICD-10-AM), Australian Classification of Health Interventions (ACHI) and Australian Coding Standards (ACS). Sydney, Australia: National Centre for Classification in Health; 2006.

20. Centre for Health Record Linkage. http://www.cherel.org.au. Accessed 15 Feb 2015.

21. Australian Bureau of Statistics. Population characteristics, Aboriginal and Torres Strait Islander Australians. ABS Catalogue No. 4713.0. Canberra: Australian Bureau of Statistics; 2006

22. Australian Institute of Health and Welfare. Australia's health system. 2016. http://www.aihw.gov.au/australias-health/2014/health-system/ Accessed 28 Apr 2016.

23. Australian Government Department of Health. National Immunisation Program Schedule. http://www.immunise.health.gov.au/internet/immunise/ publishing.nsf/Content/national-immunisation-program-schedule. Accessed 10 Oct 2016.

24. Department of Health and Aged Care. Measuring remoteness: accessibility/ remoteness index of Australia (ARIA). Canberra: Australian Government, Department of Health and Aged Care; 2001.

25. Australian Bureau of Statistics. Socio-Economic Indexes for Area (SEIFA) Technical Paper 2006. Canberra: ABS; 2008.

26. Neville SE, Taylor LK, Moore H, Madden R, Ring I, Pulver LJ, Tickle L. Using linkage between hospital and ABS mortality data to enhance reporting of deaths among Aboriginal and Torres Strait Islander peoples. Aust N Z J Public Health. 2011;35:543-8.

27. Randall DA, Lujic S, Leyland AH, Jorm LR. Statistical methods to enhance reporting of Aboriginal Australians in routine hospital records using data linkage affect estimates of health disparities. Aust N Z J Public Health. 2013; 37:442-9.

28. Taylor LK, Bentley J, Hunt J, Madden R, McKeown S, Brandt P, Baker D. Enhanced reporting of deaths among Aboriginal and Torres Strait Islander peoples using linked administrative health datasets. BMC Med Res Methodol. 2012;12:91.

29. Department of Human Services AG. After hours incentive. https://www. humanservices.gov.au/health-professionals/enablers/after-hours-incentive Accessed 10 Oct 2016

30. SAS Institute Inc. SAS Version 9.3 [software]. Cary, USA; 2010.

31. Rabash J, Browne WJ, Healy M, Cameron B, Charlton C. MLwiN Version 2.25 [software]. Centre for Multilevel Modelling. Bristol: University of Bristol; 2012.

32. Foundaton for Statistical Computing, Vienna, Austria. ISBN 3-900051-08-9, URL http://www.R-project.org/. 2012.

33. Harper S, King NB, Meersman SC, Reichman ME, Breen N, Lynch J. Implicit Value Judgments in the Measurement of Health Inequalities. Milbank Q. 2010;88:4-29.

34. Acworth J, Babl F, Borland M, Ngo P, Krieser D, Schutz J, Pitt R, Cotterell E, Jamison S, Neutze J, et al. Patterns of presentation to the Australian and New Zealand Paediatric Emergency Research Network. Emerg Med Australas. 2009:21:59-66.

35. Moore H, Burgner D, Carville K, Jacoby P, Richmond P, Lehmann D. Diverging trends for lower respiratory infections in non-Aboriginal and Aboriginal children. J Paediatr Child Health. 2007;43:451-7.

36. Moore HC, de Klerk N, Richmond P, Lehmann D. A retrospective populationbased cohort study identifying target areas for prevention of acute lower respiratory infections in children. BMC Public Health. 2010;10:757.

37. Read AW, Gibbins J, Stanley FJ. Hospital admissions for lower respiratory tract illness before the age of two years in western Australia. Paediatr Perinat Epidemiol. 1996;10:175-85.

38. Read AW, Gibbins J, Stanley FJ, Morich P. Hospital admissions before the age of 2 years in Western Australia. Arch Dis Child. 1994;70:205-10.

39. Williams P, Gracey M, Smith P. Hospitalization of Aboriginal and non-Aboriginal patients for respiratory tract diseases in Western Australia, 1988-1993. Int J Epidemiol. 1997;26:797-805.

40. Gracey M, Lee AH, Yau KK. Hospitalisation for gastroenteritis in Western Australia. Arch Dis Child. 2004;89:768-72.
41. Moore HC, Manoharan KR, Lim FJ, Shellam G, Lehmann D. Diverging trends in gastroenteritis hospitalizations during 2 decades in western Australian Aboriginal and non-Aboriginal children. Pediatr Infect Dis J. 2013;32:1169-74.

42. Yau KK, Lee AH, Gracey M. Multilevel modelling of hospitalisations for recurrent diarrhoeal disease in Aboriginal and non-Aboriginal infants and young children in Western Australia. Paediatr Perinat Epidemiol. 2005;19:165-72.

43. Australian Centre For Asthma Monitoring. Asthma In Australia 2011. AlHW Asthma Series no. 4. Cat. no. ACM 22. Canberra: AlHW; 2011.

44. Chang AB, Grimwood K, Mulholland EK, Torzillo PJ. Bronchiectasis in Indigenous children in remote Australian communities. Med J Aust. 2002;177:200-4.

45. Glasgow NJ, Goodchild EA, Yates R, Ponsonby AL. Respiratory health in Aboriginal and Torres Strait Islander children in the Australian Capital Territory. J Paediatr Child Health. 2003;39:534-9.

46. Valery PC, Chang AB, Shibasaki S, Gibsonz O, Purdie DM, Shannon C, Masters IB. High prevalence of asthma in five remote indigenous communities in Australia. Eur Respir J. 2001;17:1089-96.

47. Kearns T, Clucas D, Connors C, Currie BJ, Carapetis JR, Andrews RM: Clinic Attendances during the First 12 Months of Life for Aboriginal Children in Five Remote Communities of Northern Australia. PLoS ONE. 2013; 8:e58231. doi: 58210.51371/journal.pone.0058231.

48. Morris PS, Leach AJ, Halpin S, Mellon G, Gadil G, Wigger C, Mackenzie G, Wilson C, Gadil E, Torzillo P. An overview of acute otitis media in Australian Aboriginal children living in remote communities. Vaccine. 2007;25:2389-93.

49. Morris PS, Leach AJ, Silberberg P, Mellon G, Wilson C, Hamilton E, Beissbarth J. Otitis media in young Aboriginal children from remote communities in Northern and Central Australia: a cross-sectional survey. BMC Pediatr. 2005;5:27.

50. Williams CJ, Coates HL, Pascoe EM, Axford Y, Nannup I, Williams CJ, Coates $\mathrm{HL}$, Pascoe EM, Axford Y, Nannup I. Middle ear disease in Aboriginal children in Perth: analysis of hearing screening data, 1998-2004. Med J Aust. 2009:190:598-600.

51. DiFranza JR, Aligne CA, Weitzman M. Prenatal and Postnatal Environmental Tobacco Smoke Exposure and Children's Health. Pediatrics. 2004;113:1007-15.

52. Jacoby PA, Coates HL, Arumugaswamy A, Elsbury D, Stokes A, Monck R, Finucane JM, Weeks SA, Lehmann D. The effect of passive smoking on the risk of otitis media in Aboriginal and non-Aboriginal children in the KalgoorlieBoulder region of Western Australia. Med J Aust. 2008;188:599-603.

53. Bailie R, Stevens M, McDonald E, Brewster D, Guthridge S. Exploring crosssectional associations between common childhood illness, housing and social conditions in remote Australian Aboriginal communities. BMC Public Health. 2010; 10:147. doi: 110.1186/1471-2458-1110-1147.

54. Biddle N. Indigenous Housing Need. CAEPR Indigenous Population Project. 2011 Census Papers. No 3. Canberra: Australian National University. Centre for Economic Policy Research; 2012.

55. Mohsin M, Bauman AE. Socio-demographic factors associated with smoking and smoking cessation among 426,344 pregnant women in New South Wales, Australia. BMC Public Health. 2005;5:138.

56. Passmore $E$, McGuire $R$, Correll $P$, Bentley J. Demographic factors associated with smoking cessation during pregnancy in New South Wales, Australia, 2000-2011. BMC Public Health. 2015;15:398.

57. Arrow P. Oral health of school children in Western Australia. Aust Dent J. 2015;61(3):333-41

58. Christian B, Blinkhorn AS. A review of dental caries in Australian Aboriginal children: the health inequalities perspective. Rural Remote Health. 2012;12: 2032. Online.

59. Jamieson LM, Armfield JM, Roberts-Thomson KF, Sayers SM. A Retrospective Longitudinal Study of Caries Development in an Australian Aboriginal Birth Cohort. Caries Res. 2010:44:415-20.

60. Kruger E, Tennant M. Potentially preventable hospital separations related to oral health: a 10-year analysis. Aust Dent J. 2015;60:205-11.

61. Kruger E, Tennant M. Ten years of hospitalisation for oral health-related conditions in Western Australia: an unjust dichotomy. Aust J Prim Health. 2015:22(2):153-8.

62. Ware $\mathrm{V}-\mathrm{A}$. Improving the accessibility of health services in urban and regional settings for Indigenous people, Produced for the Closing the Gap Clearinghouse. Resource sheet no. 27. Canberra: Australian Institute of Health and Welfare \& Melbourne: Australian Institute of Family Studies; 2013.

63. Australian Government Department of Health. Quarterly Medicare Statistics September 1984 to December Quarter 2015. Canberra: Australian Government Department of Health; 2016

64. Australian Bureau of Statistics. Migration 2010-11. ABS Catalogue No. 3412. 0. Canberra: Australian Bureau of Statistics; 2012. 
65. Australian Bureau of Statistics. Australian Demographic Statistics. ABS Catalogue No. 3101.0 Table 4. Estimated Resident Population, States and Territories. Canberra: Australian Bureau of Statistics; 2012.

66. Falster MO, Jorm LR, Douglas KA, Blyth FM, Elliott MA, Leyland AH. Sociodemographic and health characteristics, rather than primary care supply, are major drivers of geographic variation in preventable hospitalizations in Australia. Med Care. 2015;53:436-45.

67. Australian Institute of Health and Welfare. Improving the quality of Indigenous identification in hospital separations data. AlHW cat. no. HSE 101. Canberra: Australian Institute of Health and Welfare; 2005.

68. Australian Institute of Health and Welfare. Indigenous identification in hospital separations data - quality report. Health Services Series no. 35. Cat. no. HSE 85. Canberra: Australian Institute of Health and Welfare; 2010.

69. Bentley JP, Taylor LK, Brandt PG. Reporting of Aboriginal and Torres Strait Islander peoples on the NSW Admitted Patient Data Collection: the 2010 data quality survey. NSW Public Health Bull. 2012;23:17-20.

70. Marmot M. Social determinants and the health of Indigenous Australians. Med J Aust. 2011;194:512-3.

\section{Submit your next manuscript to BioMed Central} and we will help you at every step:

- We accept pre-submission inquiries

- Our selector tool helps you to find the most relevant journal

- We provide round the clock customer support

- Convenient online submission

- Thorough peer review

- Inclusion in PubMed and all major indexing services

- Maximum visibility for your research

Submit your manuscript at www.biomedcentral.com/submit 